\title{
Abdominal Wall Metastasis without Primary Lesion or Definitive Diagnosis until Repeat Histology of Specimens from Laparoscopic Cholecystectomy: A Case Report
}

\author{
La Zhang ${ }^{1}$, Ning Jiang ${ }^{2}$, Rui Liao', Baoyong Zhou ${ }^{1 *}$ and Dewei $\mathrm{Li}^{3 *}$ \\ ${ }^{1}$ Department of Hepatobiliary Surgery, The First Affiliated Hospital of Chongqing Medical University, Chongqing, China \\ ${ }^{2}$ Department of Pathology, Chongqing Medical University, Chongqing, China \\ ${ }^{3}$ Department of Hepatobiliary Surgery, Chongqing University Cancer Hospital, Chongqing, China \\ *Corresponding author: Baoyong Zhou, Department of Hepatobiliary Surgery, The First Affiliated Hospital of Chongqing Medical \\ University, Chongqing, China \\ Dewei Li, Department of Hepatobiliary Surgery, Chongqing University Cancer Hospital, Chongqing, China
}

\section{ARTICLE INFO}

Received: 蔧 March 27, 2021

Published: 幽 October 29, 2021

Citation: La Zhang, Ning Jiang, Rui Liao1, Baoyong Zhou, Dewei Li. Abdominal Wall Metastasis without Primary Lesion or Definitive Diagnosis until Repeat Histology of Specimens from Laparoscopic Cholecystectomy: A Case Report. Biomed J Sci \& Tech Res 39(4)-2021. BJSTR. MS.ID.006343.

\section{ABSTRACT}

Background: Primary tumors of the abdominal wall are rare and usually metastasize from previous surgical procedures. Port-site metastasis (PSM) is a complication of laparoscopic surgery in patients with malignancy.

Case Presentation: We report a case of a female patient with PSM from gallbladder adenocarcinoma definitively diagnosed 5 years after laparoscopic cholecystectomy (LC). Two years after she first noticed a mass, fine-needle aspiration cytology of the mass yielded a definitive diagnosis and repeat histology of a gallbladder specimen from LC showed chronic cholecystitis during the postoperative histopathological examination 5 years prior.

Conclusion: This case is uncommon because of the long delay prior to the presentation of PSM, the long-term survival duration after PSM and the difficulty of identification.

Abbreviations: PSM: Port-Site Metastasis; LC: Laparoscopic Cholecystectomy; IGBC: Incidental Gallbladder Carcinoma; CT: Computed Tomography; MRI: Magnetic Resonance Imaging; CA: Carbohydrate Antigen; PET-CT - Positron Emission Tomography-Computed Tomography; PSE: Port-Site Excision

\section{Background}

Tumors located in the abdominal wall are often related to occupational and iatrogenic factors, and increased cases of abdominal wall metastases are reported along with increased removal of resected tumors by laparoscopy. Since the first laparoscopic cholecystectomy (LC) was performed in 1987, [1] LC has become the gold standard operation for benign disease of the gallbladder. With the explosive increase in LC rates, the incidence of incidental gallbladder carcinoma (IGBC), which has a more favorable prognosis than cancers presenting with symptoms, is found in $0.18-2.1 \%$ of patients during or after LC, diagnosed during or after cholecystectomy by pathology has increased [2-5]. Port-site metastasis (PSM) is a complication caused by the removal of IGBC using laparoscopic techniques, with an incidence of 14\%-29\% [6]. Several authors have reported cases of port-site adenocarcinoma 
metastasis of IGBC of unknown origin following LC. We present herein a case of PSM that was difficult to diagnose due to an incorrect histopathological examination and was discovered 3 years after LC was performed. The patient remained alive for 2 years without any treatment after the first sign of a recurrent tumor was found by the patient.

\section{Case Presentation}

A 57-year-old woman was admitted to our hospital because of aggravating pain in the right upper quadrant and a progressively enlarging mass with tenderness, measuring $20 \mathrm{~cm} \times 4 \mathrm{~cm}$, palpated at the right rectus abdominis region. The patient had undergone only one surgery, five years prior: she underwent LC using the threeport technique owing to symptomatic cholelithiasis diagnosed as chronic cholecystitis after a postoperative histological examination at an outside hospital. The patient first noticed the hard mass, measuring approximately $3 \mathrm{~cm} \times 3 \mathrm{~cm}$, with intermittent pain in the right upper abdomen 2 years prior. Then, she underwent abdominal ultrasonography, which indicated only agenesis of the gallbladder. A wait-and-see policy was adopted, and the patient was discharged from the hospital and has not received any special treatment over these 2 years.

\section{What Tests are Indicated to Narrow Down the Differential Diagnosis?}

To determine the cause of abdominal pain and the mass at the uncommon location, relevant auxiliary examinations were performed. Abdominal contrast-enhanced computed tomography (CT) showed a thickened right rectus with uneven density whose enhancement was not obvious, indicating that the mass could be a benign lesion. Abdominal contrast-enhanced magnetic resonance imaging (MRI) also showed the mass as more likely a fibroma durum. Then, an ultrasound-guided needle biopsy of the mass was performed to further clarify the nature of the mass, and metastatic adenocarcinoma tissues were found. The mass was diagnosed as a metastatic adenocarcinoma.

\section{What is the Origin of Adenocarcinoma?}

As the carbohydrate antigen (CA) 19.9 level was $367.0 \mathrm{U} / \mathrm{ml}$, above the normal range, the adenocarcinoma cell was believed to originate from the gastrointestinal tract, but no tumor foci were found on gastroscopy, colonoscopy, or whole-abdominal and pelvis enhanced CT. A positron emission tomography-computed tomography (PET-CT) scan was performed and primary lesion was not found, neither. According to abdominal MRI, the mass passed through the longitudinal section of the rectus abdominis and presented as a spindle shape near the subxiphoid laparoscopic scar. As tumors located in the skin are often related to occupational and iatrogenic factors, PMS could not be excluded. A repeat histopathologic examination of the gallbladder was performed at our hospital and revealed adenocarcinoma in the specimen. Therefore, the diagnosis was gallbladder adenocarcinoma with PMS.

\section{What is the Most Suitable Treatment for the Patient?}

On the basis of the PET-CT data and given the extensive metastases in the abdomen, a second operation to achieve radical resection was impossible, and the patient was initiated on the GP regimen (gemcitabine, cisplatin), the standard chemotherapy regimen for patients with advanced biliary tract cancer [7].

\section{Discussion and Conclusion}

Laparoscopic surgery has been widely accepted to treat benign diseases due to its desirable advantages, such as low blood loss, quick recovery, minimal pain, a short hospitalization time and few complications. Nowadays, a histological examination, which is often performed after surgery, is the gold standard for the diagnosis of benign or malignant tumors. Under these circumstances, the frequency of incidental gallbladder cancer is $0.25 \%-0.89 \%$, as demonstrated by routine histopathological investigation after LC for benign disease [8-12]. In addition, 50\%-70\% of patients are diagnosed incidentally with gallbladder cancer based on cholecystectomy specimens for presumed benign indications [13]. The prognosis of IGBC (median OS 32.4 months) is better than that of non-IGBC (median OS 17.2 months), [13] and according to the current guidelines, reoperation, including complete portal lymphadenectomy and bile duct resection, is required for patients with $\mathrm{T} 1 \mathrm{~b}, \mathrm{~T} 2$ or $\mathrm{T} 3$ disease [14].

Since the first case of PSM was reported as an unusual complication of LC in 1991, [15] many centers have reported similar cases, and the incidence of PSM in IGBC is 10.3\% [16]. Most of the metastases are found at the extraction site, [16] showing that few wound protection measures (avoiding bile spillage and using retrieval bags) may cause direct contamination and increase the risk of PSM due to the lack of awareness of possible metastases. Other factors related to laparoscopic techniques, including pneumoperitoneum and carbon dioxide, have been described as risk factors [17-19]. PSM, a manifestation of aggressive disease progression, is generally found 1 to 6 months and as late as 4 years after performing LC [6]. Port-site excision (PSE) has been considered a routine treatment, along with radical reoperation, but it has been demonstrated to have no benefits in improving survival, and recurrence at the wound site may be associated with aggressive tumor biology $[20,21]$. PSE has shown to benefit patients with PSM without other metastases $[22,23]$. Chemotherapy is now a common therapy [24]. While it is necessary to investigate a larger group of patients diagnosed with IGBC after LC is performed. PSM is thought to be associated with an advanced $\mathrm{T}$ stage and poor histopathological features [3]. The median survival duration is typically 10.3 months 
[16], while the patient described herein remained alive for 2 years without any treatment after the first sign of a recurrent tumor was found by the patient herself. Whether PSM indicates the aggressive nature of the tumor is still not clear. In addition, a longer follow-up study on patients with PSM is needed.

\section{References}

1. Polychronidis A, Laftsidis P, Bounovas A, Simopoulos C (2008) Twenty years of laparoscopic cholecystectomy: Philippe Mouret--March 17, 1987. Jsls 12(1): 109-111.

2. Kwon AH, Imamura A, Kitade H, Kamiyama Y (2008) Unsuspected gallbladder cancer diagnosed during or after laparoscopic cholecystectomy. J Surg Oncol 97(3): 241-245.

3. Søreide K, Guest RV, Harrison EM, Kendall TJ, Garden OJ, et al. (2009) Systematic review of management of incidental gallbladder cancer after cholecystectomy. Br J Surg 106(1): 32-45.

4. Kalita D, Pant L, Singh S, Jain G, Kudesia M, et al. (2013) Impact of routine histopathological examination of gall bladder specimens on early detection of malignancy - a study of 4,115 cholecystectomy specimens. Asian Pac J Cancer Prev 14(5): 3315-3318.

5. Yi X, Long X, Zai H, Xiao D, Li W, et al. (2013) Unsuspected gallbladder carcinoma discovered during or after cholecystectomy: focus on appropriate radical re-resection according to the T-stage. Clin Transl Oncol 15(8): 652-658.

6. Nakagawa S, Tada T, Furukawa H, Abe M, Hatakeyama K (2000) Latetype recurrence at the port site of unexpected gallbladder carcinoma after a laparoscopic cholecystectomy: report of a case. Surg Today 30(9): 853-855.

7. Woo SM, Lee WJ, Kim JH, Kim DH, Han SS, et al. (2013) Gemcitabine plus cisplatin versus capecitabine plus cisplatin as first-line chemotherapy for advanced biliary tract cancer: a retrospective cohort study. Chemotherapy 59(3): 232-238.

8. Lundgren L, Muszynska C, Ros A, Persson G, Gimm O, et al. (2018) Are Incidental Gallbladder Cancers Missed with a Selective Approach of Gallbladder Histology at Cholecystectomy? World J Surg 42(4): 1092 1099.

9. Koppatz H, Nordin A, Scheinin T, Sallinen V (2018) The risk of incidental gallbladder cancer is negligible in macroscopically normal cholecystectomy specimens. HPB (Oxford) 20(5): 456-461.

10. Choi KS, Choi SB, Park P, Kim WB, Choi SY (2015) Clinical characteristics of incidental or unsuspected gallbladder cancers diagnosed during or after cholecystectomy: a systematic review and meta-analysis. World J Gastroenterol 21(4): 1315-1323.

11. Dorobisz T, Dorobisz K, Chabowski M, Pawłowski W, Janczak D, et al. (2016) Incidental gallbladder cancer after cholecystectomy: 1990 to 2014. Onco Targets Ther 9: 4913-4916.

\section{ISSN: 2574-1241}

\section{DOI: 10.26717/BJSTR.2021.39.006343}

Baoyong Zhou, Dewei Li. Biomed J Sci \& Tech Res

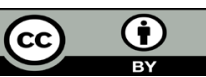

This work is licensed under Creative Commons Attribution 4.0 License

Submission Link: https://biomedres.us/submit-manuscript.php
12. Emmett CD, Barrett P, Gilliam AD, Mitchell AI (2015) Routine versus selective histological examination after cholecystectomy to exclude incidental gallbladder carcinoma. Ann R Coll Surg Engl 97(7): 526-529.

13. Ethun CG, Le N, Lopez-Aguiar AG, Pawlik TM, Poultsides G, et al. (2017) Pathologic and Prognostic Implications of Incidental versus Nonincidental Gallbladder Cancer: A 10-Institution Study from the United States Extrahepatic Biliary Malignancy Consortium. Am Surg 83(7): 679-686

14. Aloia TA, Járufe N, Javle M, Maithel SK, Roa JC, et al. (2015) Gallbladder cancer: expert consensus statement. HPB (Oxford) 17(8): 681-690.

15. Drouard F, Delamarre J, Capron JP (1991) Cutaneous seeding of gallbladder cancer after laparoscopic cholecystectomy. N Engl J Med 325(18): 1316.

16. Berger-Richardson D, Chesney TR, Englesakis M, Govindarajan A, Cleary SP, et al. (2017) Trends in port-site metastasis after laparoscopic resection of incidental gallbladder cancer: A systematic review. Surgery 161(3): 618-627.

17. Wittich P, Steyerberg EW, Simons SH, Marquet RL, Bonjer HJ (2000) Intraperitoneal tumor growth is influenced by pressure of carbon dioxide pneumoperitoneum. Surg Endosc 14(9): 817-819.

18. Bouvy ND, Marquet RL, Hamming JF, Jeekel J, Bonjer HJ (1996) Laparoscopic surgery in the rat. Beneficial effect on body weight and tumor take. Surg Endosc 10(5): 490-494.

19. Jones DB, Guo LW, Reinhard MK, Soper NJ, Philpott GW, et al. (1995) Impact of pneumoperitoneum on trocar site implantation of colon cancer in hamster model. Dis Colon Rectum 38(11): 1182-1188.

20. Fuks D, Regimbeau JM, Pessaux P, Bachellier P, Raventos A, et al. (2013) Is port-site resection necessary in the surgical management of gallbladder cancer? J Visc Surg 150(4): 277-284.

21. Maker AV, Butte JM, Oxenberg J, Kuk D, Gonen M, et al. (2012) Is port site resection necessary in the surgical management of gallbladder cancer? Ann Surg Oncol 19(2): 409-417.

22. Ciulla A, Romeo G, Genova G, Tomasello G, Agnello G, et al. (2006) Gallbladder carcinoma late metastases and incisional hernia at umbilical port site after laparoscopic cholecystectomy. G Chir 27(5): 214-216.

23. Lundberg 0, Kristoffersson A (1999) Port site metastases from gallbladder cancer after laparoscopic cholecystectomy. Results of a Swedish survey and review of published reports. Eur J Surg 165(3): 215222.

24. Rao S, Rathod A, Kamble A, Gupta D (2014) Delayed presentation of portsite metastasis from an unknown gastrointestinal malignancy following laparoscopic cholecystectomy. Singapore Med J 55(5): e73-e76.

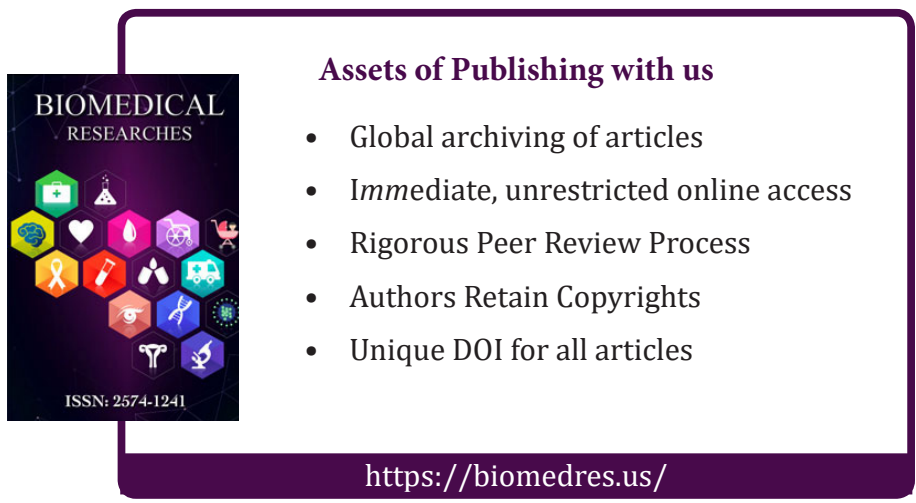

Copyright@ Baoyong Zhou, Dewei Li | Biomed J Sci \& Tech Res | BJSTR. MS.ID.006343. 